\title{
La relación entre el capital y el objeto de la sociedad en el derecho argentino*
}

\author{
The Relationship between Company's Asset and Activities \\ in Argentine Law \\ A relação entre o capital e o objeto da sociedade comercial \\ no direito argentino
}

\author{
MARTín E. AbDALA
}

FECHA DE RECEPCIÓN: 07 DE AGOSTO DE 2015. FECHA DE ACEPTACIÓN: 31 DE MARZO dE 2016

DoI: http://dx.doi.org/10.12804/revistas.urosario.edu.co/sociojuridicos/a.5268

Para citar este artículo: Abdala, M.E. (2017). La relación entre el capital y el objeto de la sociedad en el derecho argentino. Estudios Socio-Jurídicos, 19(1), 63-78. Doi: http://dx.doi.org/10.12804/revistas.urosario.edu.co/sociojuridicos/a.5268

\section{RESUMEN}

El estatuto de una sociedad debe prever cuál será su capital. La ley argentina establece una cifra mínima para constituir una sociedad anónima, pero nada dice en relación a los otros tipos societarios. Un sector de la doctrina sostiene que debe existir una adecuada relación entre el capital y el objeto de una sociedad. Se ha intentado justificar esa exigencia en las disposiciones del artículo 1 de la Ley General de Sociedades, pero resulta que esa norma no refiere siquiera a la problemática. También se pretendió fundarla en las resoluciones de la Inspección General de Justicia, pero ellas solo son exigibles a las sociedades radicadas en la Ciudad Autónoma de Buenos Aires y su constitucionalidad es, cuanto menos, dudosa. Tampoco resulta convincente justificar esa exigencia en la importancia del capital como fondo de desarrollo económico de la sociedad, pues en la actualidad, ellas ya no necesitan de recursos propios para comenzar a funcionar. No es acertado explicar esa obligación en la función de garantía del capital porque este ha perdido su importancia, y ni siquiera es considerado como un índice relevante para contratar u otorgar un crédito a la sociedad. Finalmente, se pretendió justificar la exigencia afirmando que la limitación de responsabilidad de los socios en algunos tipos de sociedad es un privilegio que solo puede concederse cuando la sociedad tiene un capital adecuado; sin embargo, entendemos que ese requisito se cumple si la sociedad satisfizo la cifra mínima exigida por la ley,

* Este artículo es resultado del proyecto de investigación titulado "La Responsabilidad de los Administradores Societarios", actualmente en curso, financiado por el Consejo Nacional de Investigaciones Científicas de la República Argentina y en la cual el autor participa en calidad de investigador.

** Doctor en Derecho por la Universidad de Colonia (Alemania). Investigador del Consejo Nacional de Investigaciones Científicas, Argentina. Profesor de Derecho Comercial de la Universidad Nacional de Tucumán, Argentina. Correo electrónico: martinabdala@arnet.com.ar 
y no puede por ello abrogarse la limitación de la responsabilidad arguyendo que esa cifra no corresponde al objeto societario.

Palabras clave: Sociedades, capital, objeto, infracapitalización.

\section{ABSTRACT}

The agreement creating a company must establish its capital. Argentine law sets a minimum capital in order to constitute a corporation, but it says nothing about other types of companies. Some authors state that there must be a proper relationship between the asset and the object or economic purpose of the company. Some justify this requirement in the provisions of article 1 of the Ley General de Sociedades, but this law does not refer to this subject. They also tried to justify this requirement with the internal decisions of the Inspección General de Justicia, but those are only mandatory for companies based in Buenos Aires, and its constitutionality is, at least, doubtful. Neither is it convincing to justify this requirement on the importance of resources as a base of the company's economic development, because companies nowadays do not need to have their own resources to start functioning. Also, it is not correct to explain that duty on the guarantee function of asset, because it has lost its importance, and it is not even considered as a relevant index for contracting or grating a credit to the company. Finally, some authors justify that demand arguing that the limitation of the partner's duties, in some companies, is a privilege, which can only be granted when the company has adequate funds. However, we think that this requirement is met if the company fulfils the minimum asset required by law, and the limitation of liability cannot be abrogated by arguing that this minimum does not match the purpose of the company.

Keywords: Corporations, asset, activities, undercapitalization.

\section{RESUMO}

O estatuto de uma sociedade deve prever qual será o seu capital. A lei argentina prevê uma cifra mínima para constituir uma sociedade anónima, mas nada diz em relação aos outros tipos societários. Um setor da doutrina sustenta que deve existir uma adequada relação entre o capital e o objeto. Se tem tentado justificar essa exigência nas disposições do art. 1 da lei geral de sociedades, mas resulta que essa norma não refere sequer à problemática. Também se pretendeu fundá-la nas resoluções da Inspeção Geral de Justiça, mas elas só são exigíveis às sociedades radicadas na Cidade Autónoma de Buenos Aires e a sua constitucionalidade é, quanto menos, duvidosa. Também não resulta convincente justificar essa exigência na importância do capital como fundo de desenvolvimento econômico da sociedade, pois na atualidade, elas já não precisam de recursos próprios para começar a funcionar. Não é acertado explicar essa obrigação na função de garantia do capital, porque este tem perdido a sua importância como tal e nem sequer é considerado como um índice relevante para contratar ou outorgar um crédito à sociedade. Finalmente se pretendeu justificar a exigência afirmando que a limitação de responsabilidade dos sócios em alguns tipos é um privilégio que só pode conceder-se quando a sociedade tenha um capital adequado, no entanto, entendemos que este requisito se cumpre se a sociedade satisfez a cifra mínima exigida pela lei e não pode por isso ab-rogar-se a limitação da responsabilidade arguindo que essa cifra não corresponde ao objeto societário.

Palavras-chave: Sociedades Comerciais, capital social, objeto social, infracapitalização. 


\section{Planteamiento del problema e hipótesis de trabajo}

La creación de una sociedad presupone que los socios realicen aportes con los que se forma el capital de la nueva persona jurídica. En el derecho argentino, conforme lo establece el inciso 4 del artículo 11 de la Ley General de Sociedades, el instrumento de constitución de una sociedad (el estatuto) debe prever de manera expresa la cuantía de ese capital (expresado en moneda argentina) y debe mencionar el aporte de cada socio'. Sin embargo, la mentada Ley General de Sociedades no precisa ni determina cuáles son los montos mínimos de capital que deben satisfacerse en cada uno de los diferentes tipos societarios admitidos en el ordenamiento positivo. Solo para la sociedad anónima, establece el artículo 186 de la Ley General de Sociedades, que debe fijarse una cifra mínima de capital ${ }^{2}$, sin que exista una norma similar para los restantes tipos de sociedades como las de responsabilidad limitada, las colectivas, las de capital e industria, etc ${ }^{3}$.

La importancia de esa omisión es minimizada por un sector de la doctrina vernácula que sostiene que la previsión normativa que exige dotar a este tipo de persona jurídica con una cifra mínima de capital tiene una importancia menor y que lo que realmente interesa es que exista una adecuada y razonable relación entre el capital y el objeto de la sociedad (Zaldívar, Manóvil, Ragazzi \& Rovira, 1976), entendido este último como el conjunto de actividades previstas en el estatuto fundacional que los socios se proponen cumplir bajo el nombre social ${ }^{4}$ (Colombres, 1972).

1 Una exigencia similar preveía el artículo 1649 del Código Civil (hoy derogado) para las sociedades civiles, y establecía que los socios deben aportar prestaciones de dar o de hacer y que, las primeras, integrarían el capital social (Halperín, 1966).

2 Ese monto debe ser periódicamente revisado cuando el Poder Ejecutivo Nacional lo considere necesario. Sin embargo, y a pesar de los altos índices de inflación que durante muchos periodos económicos ha tenido Argentina, esta cifra se mantuvo durante muchos años en $\$ 12000$. En el 2012 fue elevada a $\$ 100000$ por el decreto 1331/2012 y desde entonces no se modificó, a pesar de que la inflación real acumulada desde entonces es de más del 80\%.

3 En el caso de las Sociedades de Responsabilidad Limitada (SRL), cuando la ley 11645 las incorporó en el derecho argentino, exigía a estas un capital mínimo, pero la reforma normativa que plasmó la ley 19550 no reeditó ese requisito. Un sector de la doctrina sostiene que el abandono del capital mínimo obedeció a que, de otra manera, los procesos inflacionarios terminarían por permitir que se formasen sociedades con capitales exiguos (Mascheroni, 1979).

4 En esa dirección, Halperín (1972), quien afirma que en realidad no interesa que nazca 
Así las cosas, el propósito de este artículo es analizar los argumentos con los que se justifica y fundamenta esa tesis y sopesar las eventuales consecuencias de su inobservancia.

Nuestra hipótesis de trabajo es que, de lege lata, no existe en el ordenamiento positivo societario argentino una norma que obligue a las sociedades a tener un capital que se adecue a su objeto y que, de lege ferenda, la conveniencia de su introducción es, cuanto menos, dudosa. ${ }^{5}$

En los próximos acápites analizaremos entonces los fundamentos dogmáticos a los que se recurre para justificar la exigencia de que exista una adecuada relación entre el objeto y el capital de la sociedad y constataremos, en cada caso, si ellos son correctos y pueden efectivamente utilizarse con ese propósito.

\section{Argumentos para justificar la exigencia de una relación entre objeto y capital social}

\section{El artículo 1 de la Ley General de Sociedades}

En una visión cuanto menos sutil, un sector de la doctrina afirma que la exigencia de una adecuada relación entre el capital y el objeto de una sociedad deriva del artículo 1 de la Ley General de Sociedades que, recordemos, establece que habrá sociedad comercial cuando una o más personas "se obliguen a realizar aportes para aplicarlos a la producción o intercambio de bienes o servicios".

Con ese punto de partida, la redacción de esa norma, puede inferirse la intención del legislador de imponer la obligación de que exista una relación de suficiencia o, cuanto menos, de mínima proporcionalidad entre el capital y el objeto de la sociedad (Butty, 1989; Nissen, 2000).

Por nuestra parte no podemos coincidir con esta interpretación, pues consideramos que, ni de la redacción ni del espíritu del artículo 1 de la

\footnotetext{
un gran número de sociedades, sino que estas sean viables y cuenten con medios que aseguren una vida ulterior próspera.

5 Las razones por las que sostenemos que es dudosa la conveniencia de la introducción de una norma que obligue a las sociedades a tener un capital que se adecue a su objeto, son explicadas en los siguientes acápites.
} 
ley puede concluirse la exigencia de la mentada obligación, puesto que el deber de realizar aportes y el destino que ellos tendrán (en este caso la producción o el intercambio de bienes y servicios) no está en ese artículo ni cuantificado ni calificado, razón por la que entendemos que esa norma no es útil para justificar la exigencia que analizamos, excepto que se fuerce al extremo la interpretación de la misma y se la haga decir algo que, en realidad, ella no dice.

Es cierto, y no lo desconocemos, que existen reglas de interpretación de las normas jurídicas que permiten modificar su alcance y extenderlo (interpretación modificativa extensiva) ${ }^{6}$ cuando ellas fueron expresadas con excesiva estrechez ${ }^{7}$, pero también es cierto que ese método de interpretación no puede ser el pretexto para sacar conclusiones distantes, que no pudieron siquiera ser avizoradas en el momento de sancionarse la mentada norma, razón por la que no surgen ni de la letra ni del espíritu de la misma.

Y justamente ello es lo que ocurre si se pretende justificar con lo dispuesto en el artículo 1 de la Ley General de Sociedades, la exigencia de que exista relación entre el objeto y el capital de una sociedad comercial, lo cual -como referimos- no fue siquiera vislumbrado por el legislador al sancionar dicha norma.

\section{Las resoluciones de la Inspección General de Justicia}

También se ha justificado la exigencia de una adecuada relación entre objeto y capital social con las disposiciones contenidas en diferentes

6 Recordemos que la interpretación de una norma puede ser declarativa o modificativa, atendiendo al alcance o extensión que el procedimiento de exégesis le otorgue. La interpretación declarativa es la más corriente y su objeto es el de explicar el texto de la ley, para lo cual se ciñe a lo que dice la norma, limitándose a aplicarla a los supuestos estrictamente comprendidos en ella, razón por la que se la concibe y nomina como interpretación gramatical o literal. La interpretación modificativa, en cambio, modifica o endereza el alcance de la norma cuando esta se aparta de la originaria intensión del legislador y puede ser, a su vez, extensiva o restrictiva. La interpretación modificativa extensiva amplía el alcance de la norma, mientras que la interpretación modificativa restrictiva, por el contrario, limita el significado propio de la expresión usada por la ley, restringiendo el alcance de la norma y apartando supuestos que se encontrarían incluidos de acuerdo con la redacción de su texto, pero que se entiende que no fue voluntad del legislador comprenderlos dentro de esta (Trabucchi, 1967, p. 49).

7 Si resulta que la norma en su sentido lingüístico usual se queda a la zaga de la voluntad auténtica de su autor, hay que ensancharla para que llegue a alcanzarlo (Goldschmidt, 1983). 
resoluciones de la Inspección General de Justicia de la Ciudad Autónoma de Buenos Aires -en adelante IGJ- (Nissen, 2000).

Ya en los años 80 la IG dictó una resolución general ${ }^{8}$ en cuyo artículo 18 , luego de admitir que las sociedades podían incluir como objeto social en el acto constitutivo una pluralidad de actividades, exigió que esas actividades guarden una razonable relación con el capital social.

En el año 2004, ese organismo reforzó su postura y dictó la resolución general número 9/04 que modificó el artículo 18 de la resolución general número 6/80 y estableció que el objeto de la sociedad, como conjunto de actividades que se propone realizar el ente, debe ser único y su mención debe efectuarse en forma precisa y determinada, mediante la descripción concreta y específica de las actividades que contribuirán a su efectiva consecución, precisando luego que será admisible la inclusión de otras actividades (también descritas en forma precisa y determinada) únicamente si las mismas son conexas, accesorias o complementarias de las actividades que conducen al desarrollo del objeto social y que el conjunto de dichas actividades guarden razonable relación con el capital social.

En esa resolución se dispuso también que la IGJ puede exigir una cifra superior a la fijada en el acto constitutivo (aun en la constitución de sociedades por acciones con la cifra mínima del artículo 186 de la Ley General de Sociedades) si advierte que, en virtud de la pluralidad de actividades, el capital social resulta manifiestamente inadecuado.

Posteriormente, el artículo 66, último párrafo de la resolución general de la IG número 7 del 2005, estableció algo similar y dispuso que el objeto social debe ser único, que su mención debe efectuarse en forma precisa y determinada, y que el conjunto de las actividades descritas debe guardar razonable relación con el capital social.

Sin duda, estas resoluciones de la IGJ podrían representar un serio argumento a favor de la obligatoriedad de que exista una relación entre el objeto y el capital de una sociedad.

Sin embargo, ese fundamento pierde importancia si se considera, por un lado, que en virtud de la organización federal de nuestro país las mentadas resoluciones obviamente son solo y únicamente aplicables a las sociedades radicadas en la jurisdicción en donde la IGJ tiene competencia

8 Resolución número 6/80 de la IGJ. 
(esto es la Ciudad Autónoma de Buenos Aires) y, por otro lado, que la constitucionalidad de esas resoluciones es, cuanto menos, dudosa.

En efecto, la conformidad de las citadas resoluciones con las normas y principios constitucionales de la Argentina ingresa en una zona de crisis cuando se advierte que imponer a las sociedades obligaciones para su constitución, que no están previstas en la Ley General de Sociedades, adolece de dos gruesos defectos: excede el marco de competencia funcional de la IGJ, pues resulta exorbitante para las funciones de registración que le otorga la normativa que crea ese ente (Ley 22135, 1980, artículo 2) y vulnera la jerarquía normativa de nuestro ordenamiento jurídico, representada por Kelsen como una pirámide jurídica y por Austin como un sistema de arborescencia (Raz, 1986), en tanto una norma de menor rango - una resolución de la IGJ- pretende modificar sustancialmente una norma de grado superior - la Ley General de Sociedades-, imponiendo exigencias para la creación de sociedades que no fueron previstas ni contempladas en esta última.

\section{El capital como fondo del desarrollo de las actividades de la sociedad}

En igual dirección se ha intentado justificar el deber de que exista una adecuada relación entre el objeto y el capital, dada la importancia de este último como fondo de desarrollo económico de la sociedad (Halperín, 1972).

En efecto, recordemos que una de las finalidades del capital de una sociedad es ser el fondo común al que se recurre para poder financiar sus actividades. Los bienes aportados por los socios fundadores (normalmente dinero en efectivo, vehículos, inmuebles, muebles, útiles, etc.) son entonces una fuente genuina para financiar las actividades del ente en esa etapa fundacional y hasta tanto este genere sus propios recursos (Manóvil, 1996, p. 601).

En ese orden de ideas, y en una suerte de sobreestimación de la importancia del capital social como fondo de desarrollo, se sostiene que es imprescindible que la cifra prevista en el estatuto guarde relación con el objeto de la sociedad e incluso se afirma que si ello no ocurre, no debe siquiera inscribirse la misma en el registro público de comercio (Butty, 1989). 
Nos permitimos discrepar con esa tesis fundamentalmente porque creemos que la importancia de la función del capital social como fondo de desarrollo de la sociedad es hoy dudosa. Por un lado, porque en la actualidad las sociedades no necesitan, ni siquiera en la etapa fundacional, de recursos propios para comenzar a funcionar, pues el sistema capitalista moderno permite un fácil acceso al crédito (empréstitos, emisiones de títulos mobiliarios, cotización en la bolsa de valores, etc.) y la sencilla posibilidad de postergar los desembolsos económicos (mediante la emisión de cheques de pago diferido, títulos de crédito, etc.) hasta que la sociedad genere sus recursos propios, sin necesidad de echar mano del capital originario (López Tilli, 2010). Por otro lado, porque la cifra de capital prevista en el estatuto es normalmente superada al poco tiempo de iniciarse las actividades societarias, y es habitual que las sociedades, a poco de andar, tomen créditos de sus propios socios o de terceros, incrementado de esa manera la disponibilidad económica para perseguir sus objetivos, lo cual disminuye sustancialmente el rol y la importancia de la cifra consignada en el estatuto y de los montos aportados por los socios en el momento fundacional del nuevo ente.

Por lo demás, y en lo que respecta a la posibilidad de negar la inscripción de una sociedad por la falta de una adecuada relación entre el capital y el objeto, creemos que ello es un exceso, y que se trata de una determinación que se encuentra fuera de la órbita de competencia y de las facultades del registro público de comercio.

Precisar cuál es el capital adecuado que debe tener una sociedad para cumplir su objeto es una tarea sumamente compleja, sobre todo, porque es muy frecuente que estas personas jurídicas, para evitar realizar permanentes modificaciones en el estatuto, prevean objetos amplios y ambiciosos, que la mayoría de las veces no son ni remotamente los que en definitiva perseguirán, razón por la que mal podría sopesarse si el capital previsto por una sociedad se ajusta a las necesidades de su objeto cuando, en realidad, no se sabe a ciencia cierta cuál será la real actividad de la misma.

Además, es sumamente difícil establecer criterios objetivos que permitan saber si un determinado monto de capital será suficiente para cumplir el objeto societario, criterios sin los cuales se ofrece un flanco abierto de discrecionalidad y arbitrariedad de quienes deban ejercer el 
control. Y justamente con relación a este punto, es también muy complejo determinar cuál organismo o funcionario tendrá la tarea, deber y responsabilidad de juzgar cuál es el capital adecuado que debe tener una sociedad en función de su objeto.

Es cierto, y no lo desconocemos, que un sector de los autores y de la jurisprudencia sostienen que esas funciones son competencia del registrador (Nissen, 2000), pero entendemos que esa delegación doctrinaria y pretoriana (pues no hay ninguna norma que lo haga) es impropia porque significa otorgar a ese funcionario tareas que exceden sus conocimientos, preparación y competencias, y lo obligan a tomar decisiones que, en definitiva, resultan infundadas y arbitrarias.

\section{La función de garantía del capital social}

También se pretendió justificar la necesidad de que exista una adecuada relación entre el objeto y el capital de una sociedad en la función de garantía patrimonial que tiene este último frente a terceros que, de una u otra manera, se vinculan con el ente y resultan -a la postre- sus acreedores, sea porque contratan con la sociedad (y tienen con ella vínculos comerciales, laborales, etc.) o bien porque tienen una acreencia derivada de la responsabilidad extracontractual.

En ese orden de ideas, se afirma que cuando el capital de una sociedad no es congruente o es desproporcionado con su objeto, no puede cumplir su función de "cifra de retención" del patrimonio impuesta por la ley en garantía de los acreedores de la sociedad y en seguridad del cobro de sus créditos (Chuliá, 1986). Cuando ello ocurre, se traslada el riesgo empresario de los socios a los acreedores de la sociedad, que pueden resultar víctimas de un engaño ya que, lo que se presenta en el mercado como una empresa sólida y próspera, puede en realidad ser una firma sin solvencia para afrontar sus obligaciones.

Además, se afirma que cuando no existe una adecuada correspondencia entre el capital y el objeto, la sociedad se encuentra en una situación de "pérdida del capital" o de "imposibilidad (ex origine o sobreviniente) de cumplir su objeto", circunstancias en las que la misma no puede girar y debe disolverse en virtud de lo dispuesto por los incisos 4 y 5 del 
artículo 94 de la Ley General de Sociedades (Nissen, 2000)9 ; incluso se sostiene que cuando esa incongruencia se presenta en la etapa fundacional de la sociedad, debe denegarse la inscripción de la misma en el registro público de comercio $^{10}$.

A pesar de que el razonamiento expuesto en los párrafos anteriores puede parecer en una primera aproximación atractivo, creemos que cuando se lo analiza en profundidad tiene una lógica vulnerable, fundamentalmente, porque el capital social ha perdido en los tiempos actuales su importancia y utilidad como garantía para los acreedores de la sociedad.

En efecto, el capital ya no es considerado como un índice relevante para tomar la decisión de celebrar un contrato con una sociedad o para otorgarle crédito (Roitman, 2006). En ambos casos, el cotejo de la cifra consignada en el estatuto cedió su importancia a la indagación de la verdadera situación patrimonial de la sociedad (que será - en definitiva- la única manera de sopesar su solvencia) y de su liquidez, determinada por los flujos de fondos esperados - cash flow- (Ross, Westerfield \& Jaffe, 2002; Kieso, Weygandt \& Warfield, 2013).

Por esos motivos, la falta de una adecuada relación entre el capital y el objeto de la sociedad, no implica inexorablemente, ni puede ser asimilada a la situación de pérdida del capital, ni significa, mucho menos, la imposibilidad de lograr el cumplimiento del objeto societario.

Por otro lado, es dudoso que la falta de congruencia entre el objeto y el capital social implique trasladar el riesgo empresario de los socios a la comunidad porque -como referimos- en las economías modernas las empresas tienen amplias posibilidades de asistencia crediticia, (mediante empréstitos, emisiones de títulos mobiliarios o cotización en la bolsa de valores, etc.) lo cual disminuye sustancialmente el rol y la importancia del capital consignado en el estatuto y aportado por los socios en el momento fundacional del nuevo ente.

En ese orden de ideas, son los financistas (y no la comunidad como impropiamente se piensa) quienes asumirán los riesgos derivados de la 
falta de adecuación entre el capital y la actividad que se propone realizar una sociedad, lo cual a la postre es sumamente positivo, pues obviamente ellos tienen mejores y mayores conocimientos que un funcionario del órgano de control (por ejemplo el registrador de la IGJ) para sopesar planes de negocio, estructuras de financiamiento, evolución de ingresos y egresos, etc.

Por lo demás, resulta paradójico que, en estos tiempos en los que la propia noción del capital social está en crisis ${ }^{11}$, un sector de la doctrina no solo sostenga su importancia, sino que incluso exacerbe la misma, exigiendo que tenga una adecuada relación con el objeto de la sociedad ${ }^{12}$.

\section{La abrogación de la limitación de la responsabilidad}

Finalmente, se pretendió justificar la necesidad de que exista una adecuada relación entre objeto y capital, con la limitación de responsabilidad de los socios que prevén ciertos tipos societarios, como por ejemplo las sociedades anónimas y las de responsabilidad limitada.

Recordemos que la mayoría de las legislaciones occidentales contemplan la posibilidad de constituir sociedades en las cuales la responsabilidad de los socios se circunscriba a concretar los aportes comprometidos y, en consecuencia con ello, no deban estos atender con su propio patrimonio las obligaciones contraídas por el ente del que forman parte que, por cualquier motivo, resulten insatisfechas.

Con ese punto de partida, se sostiene que esa limitación de la responsabilidad es un privilegio o prerrogativa que solo puede concederse en aquellos casos en los que la sociedad tenga una adecuada provisión de capital, razón por la cual las situaciones de infracapitalización repercuten directamente en la acotación de responsabilidad de los socios, reduciéndola y hasta abrogándola (Gricioni, 2004).

11 Recordemos que muchos autores minimizan la importancia de las funciones y del propio capital social, hasta el punto de considerarlo fútil (Le Pera, 1986).

12 Por eso consideramos acertada la posición de los autores que proponen repensar tanto la noción de capital, cuanto las funciones que corresponde atribuirle, asumiendo que el criterio tradicional establecido en nuestra ley de sociedades ha entrado en crisis, siendo la del año 1972 una concepción ortodoxa de capital social (Araya, 1996). 
Esta tesis afirma entonces que la infracapitalización permite que se responsabilice a sus socios y controlantes por las obligaciones insatisfechas de la sociedad; cuando ella fuera originaria (es decir, cuando surja de la misma constitución de la sociedad) todos los accionistas deben responder por las obligaciones sociales, sin posibilidad de invocar el beneficio de la limitación de la responsabilidad. Cuando es sobreviviente, la inoponibilidad del beneficio de la limitación de la responsabilidad es directamente aplicada a los socios controlantes (Gricioni, 2004), y a los socios que, sin serlo, puedan y deban conocer la situación económica y financiera de la sociedad, en este último caso deberá analizarse la conducta del accionista frente a la aprobación de los balances, aumentos de capital, etc. (Nissen, 2000) ${ }^{13}$.

Ahora bien, a pesar de que en una primera aproximación los postulados de esta tesis son seductores, las primeras debilidades aparecen a la hora de precisar cuándo debe considerarse que una sociedad está en una situación de infracapitalización, pues en nuestra opinión ello no ocurre cuando la sociedad previó la cifra mínima exigida por la ley societaria, aun cuando ella no resulte proporcional o adecuada al objeto que el ente se propone realizar.

Ello es así por cuanto, aun cuando fuera cierto que la limitación de la responsabilidad de los socios en algunas sociedades es un privilegio que exige como obvia contrapartida que se otorgue al ente un capital adecuado, no deriva de ello que ese capital deba ajustarse al objeto social, sino que solamente implica que deben satisfacerse los mínimos legales previstos por la legislación societaria.

Por otro lado, la impropia relación entre el capital y el objeto de una sociedad no puede afectar, ni mucho menos implicar la derogación de la limitación de la responsabilidad de los socios, por cuanto esa prerrogativa no puede abrogarse con liviandad, sin una adecuada justificación dogmática.

Y obviamente esa justificación no es adecuada cuando ella no deriva de la inobservancia de una norma que impone la obligación de adecuar 
el capital al objeto de la sociedad, sino únicamente de la contradicción de opiniones doctrinarias y antecedentes pretorianos.

Distinto sería el caso si nuestro ordenamiento positivo previera la obligación de las sociedades de fijar su capital de acuerdo al objeto que el ente se proponga realizar, pues en ese supuesto estaría justificado que la inobservancia de ese deber conllevaría a la abrogación del beneficio de la limitación de la responsabilidad de los socios.

Sin perjuicio de ello no podemos ni por un momento olvidar que la falta de adecuación del objeto al capital social puede funcionar como una causa que justifique la sindicación de responsabilidad a los controlantes y administradores societarios que fundaron la sociedad, aunque en este caso el deber reparatorio podrá fundarse en la culpa in contrahendo (Abdala, 2010) ${ }^{14}$.

\section{Conclusiones}

El instrumento de constitución de una sociedad comercial debe prever cuál será el capital del ente. La ley societaria argentina prevé una cifra mínima de capital para constituir una sociedad anónima, pero nada dice en relación a los otros tipos societarios. Un sector de la doctrina resta importancia a esas previsiones normativas y sostiene que, en realidad, lo que interesa es que exista una adecuada y razonable relación entre el capital y el objeto de la sociedad.

Se ha intentado justificar esa exigencia en las disposiciones del artículo 1 de la Ley General de Sociedades, pero resulta que esa norma no se refiere a la problemática, razón por la cual ni siquiera aplicando una regla de interpretación de la norma jurídica modificativa extensiva puede inferirse que el objetivo de la misma sea imponer la obligación de una relación entre el objeto y el capital de una sociedad.

También se pretendió fundar esa obligación en las resoluciones dictadas por la Inspección General de Justicia, pero ocurre que, por un lado, ellas solo son exigibles a las sociedades radicadas en la jurisdicción donde ese organismo es competente (la Ciudad Autónoma de Buenos Aires)

14 Véase al respecto Jhering (1861); Larenz (1975); Canaris (1964). 
y, por otro lado, la constitucionalidad de esas resoluciones es, cuanto menos, dudosa.

Tampoco resultan convincentes los argumentos de quienes pretenden justificar la exigencia de una adecuada relación entre capital y objeto de la sociedad en la importancia de este último como fondo de desarrollo económico de la sociedad, pues, por un lado, en la actualidad las sociedades no necesitan ni siquiera en la etapa fundacional, de recursos propios para comenzar a funcionar (ya que el sistema capitalista permite un fácil acceso al crédito) y, por otro lado, porque la cifra de capital prevista en el estatuto es normalmente superada al poco tiempo de iniciarse las actividades, lo cual disminuye sustancialmente su rol e importancia.

Del mismo modo discrepamos con la tesis que propone justificar la exigencia de que exista una adecuada relación entre el objeto y el capital de una sociedad en la función de garantía patrimonial que tiene este último frente a terceros, porque en los tiempos actuales el capital social ha perdido su importancia como garantía para acreedores y ya no es considerado como un índice relevante para celebrar un contrato $u$ otorgar un crédito a una sociedad.

Finalmente, se pretendió justificar la mentada exigencia con la limitación de responsabilidad de los socios que prevén ciertos tipos societarios, afirmando que ella es un privilegio que solo puede concederse cuando la sociedad tenga una adecuada provisión de capital. Discrepamos con esta posición, de un lado, por cuanto entendemos que una sociedad que satisfizo la cifra mínima exigida por la ley societaria no está en situación de infracapitalización, aun cuando ese capital no sea proporcional al objeto y, por el otro, porque creemos que la abrogación del privilegio de la limitación de la responsabilidad es una medida extrema que no puede adoptarse con liviandad y sin una adecuada justificación dogmática.

\section{Referencias}

Abdala, M. (2010). Responsabilidad de los administradores por infracapitalización: imputación fundada en la culpa in contrahendo. En R. Nissen (Comp.), Libro de ponencias del XI Congreso Argentino de Derecho Societario (pp. 555-559). Buenos Aires: Fidas 
Araya, M. (1996). Problemas actuales del capital social. En R. Nissen (comp) Libro de ponencias del Primer encuentro Argentino-Uruguayo de Institutos de Derecho comercial (pp. 74-78). Mar del Plata: Fidas.

Argentina, Cámara Nacional Civil y Comercial de Santa Fe. Fallo in re "Bocca SAS/Inscripción" (2 de abril de 2006).

Argentina, Inspección General de Justicia. Ley 22135 de 1980 (31 de octubre de 1980).

Argentina, Inspección General de Justicia. Resolución General 6 de 1980 (24 de diciembre de 1980).

Argentina, Inspección General de Justicia. Resolución General 9 de 2004 (4 de junio de 2004).

Argentina, Inspección General de Justicia. Resolución General 7 de 2015 (28 de julio de 2015).

Bosch Colombres, G. R. (1972). Curso de Derecho Societario. Buenos Aires: Abeledo-Perrot.

Butty, E. (1980). Fallo Veca Constructora S.R.L. Revista Jurídica Argentina La Ley, 1980-D, 464-470.

Canaris, C. W. (1964). Geschäfts- und Verschuldensfähigkeit bei Haftung aus culpa in contrahendo, Gefährdung und Aufopferung. Neue Juristische Wochenschrift, 42, 1987-1993.

Chuliá, F. V. (1986). Compendio crítico de derecho mercantil Madrid: Librería.

Goldschmidt, W. (1983). Introducción Filosófica al Derecho. Buenos Aires: Depalma.

Gricioni, M. G. (2004). Consideraciones acerca del control registral de la infracapitalización originaria. Sociedades Comerciales. Suplemento Especial Revista Jurídica Argentina La Ley, 71-84.

Halperín, I. (1972). Sociedades de Responsabilidad Limitada. Buenos Aires: Depalma. Halperín, I. (1966). Sociedades Comerciales Buenos Aires: Depalma.

Kieso, D., Weygandt, J. E Warfield, T. (2014). Intermediate Accounting. Nueva York: Wiley.

Larenz, K. (1975). Bemerkungen zur Haftung für culpa in contrahendo. En Beiträge zum Zivil- und Wirtschaftsrecht: Festschrift für Kurt Ballerstedt zum 70. Geburtstag (pp. 400-403). Berlin: Duncker \& Humblot.

Le Pera, S. (1986). Sobre la futilidad de la noción de capital social. En Revista Jurídica Argentina La Ley, 1986-B, 972-979.

Lopez Tilli, A. (2010). La infracapitalización no es el problema. Incapacidad de nuestro sistema legal para velar por la traslación eficiente del riesgo. En R. Nissen (Comp.), Libro de ponencias del XI Congreso Argentino de Derecho 
Societario y VII Congreso Iberoamericano de derecho societario y de la empresa II (pp. 311-315). Mar del Plata: Fides.

Manóvil R. (1996). Responsabilidad de los socios por insuficiencia de capital propio. El modelo alemán. En O. Gómez Leo (Comp.), Cuadernos de la Universidad Austral - Derecho Empresario Actual - Homenaje al Dr. Raymundo Fernandez, (pp. 601-619) Buenos Aires: Depalma.

Mascheroni, F. H. (1979). Manual de Sociedades de Responsabilidad Limitada, Buenos Aires: Abeledo Perrot.

Nissen, R. (2000). Panorama actual de derecho societario. Buenos Aires: Ad Hoc.

Raz J. (1986). El concepto de sistema jurídico. México: Universidad Nacional Autónoma de México.

Roitman, H. (2006). Ley general de sociedades comentada y anotada. Buenos Aires: La Ley.

Ross, S., Westerfield R. E Jaffe, J. (2002). Corporate Finance. Nueva York: McGraw-Hill.

Trabucchi, A. (1967). Instituciones de Derecho Civil Tomo I. Madrid: Editorial Revista de Derecho Privado.

von Jhering, R. (1861). Culpa in contrahendo oder Schadensersatz bei nichtigen oder nicht zur Perfection gelangten Verträgen. En Jahrbücher für die Dogmatik des heutigen römischen und deutschen Privatrechts (pp. 1-112). Jena: Druck und Verlag von Friedrich Maute

Zaldivar, E., Manóvil, R., Ragazzi, G. \& Rovira, A. (1976). Cuadernos de Derecho Societario III Buenos Aires: Abeledo-Perrot. 